\title{
Infection rates after tympanostomy tube insertion, comparing Aboriginal and non-Aboriginal children in the Northern Territory, Australia: a retrospective, comparative study
}

\author{
P Jassar, A Sibtain, D Marco*, J Jose, G Hunter $\dagger$
}

\begin{abstract}
Objective: To determine if there is a difference in infection rates between Aboriginal and non-Aboriginal children, following tympanostomy and ventilation tube placement, in the Northern Territory, Australia.

Materials and methods: A cohort of 213 patients aged zero to 10 years who had undergone tympanostomy and ventilation tube placement at the Royal Darwin Hospital between 1996 and 2004 were identified. Patients were divided into Aboriginal or non-Aboriginal groups, from their medical record. Factors such as age, sex, dwelling (remote or urban) and season were compared for each group, in order to ascertain if they contributed to infection rates. A retrospective analysis of cases was conducted for the two-year post-operative period.

Results: There was no statistically significant difference in infection rates between the two groups ( $37 \mathrm{vs}$ 35 per cent). There was no statistically significant difference when comparing the two groups for age, sex, season, or remote $v s$ urban dwelling.

Conclusion: Aboriginal children were not prone to more infections following tympanostomy tube placement when compared with non-Aboriginal children.
\end{abstract}

Key words: Otitis Media With Effusion; Ventilation Tube; Otorrhoea; Australia

\section{Objectives}

This comparative, retrospective study was designed to ascertain if there was a difference in infection rates between indigenous and non-indigenous children of the Northern Territory, Australia, following tympanostomy tube insertion for middle-ear infection.

\section{Materials and methods}

We selected a cohort of patients aged zero to 10 years who had undergone tympanostomy tube placement at the Royal Darwin Hospital between 1996 and 2004, for treatment of otitis media with effusion (OME) and/or recurrent acute otitis media. The primary outcome measure of this study was the rate of infection in the two-year period following tympanostomy tube insertion, in relation to patients' age, race, sex and dwelling. A search of the hospital's computer database, using the search term 'myringotomy with insertion of tubes', yielded a record of all patients undergoing surgery during 1996-2004. Preliminary screening of the medical records excluded patients who: (1) were more than 10 years old; (2) had undergone tympanostomy tube insertion for indications other than OME or recurrent acute otitis media; (3) were deceased; and (4) had missing medical records.

In order to facilitate data collection, qualitative data sheets were constructed. From each patient's medical records, the following data were collected for the two years post-operatively: age; race (indigenous (i.e. Aboriginal) or non-indigenous); sex; month of surgery; month of the sequelae in question; and dwelling (i.e. remote (Northern Territory) or urban (Darwin and suburbs)).

Within the patients' medical records, the following key words were taken to indicate post-operative infection: 'otorrhoea', 'runny ear', 'infection', 'grommet infected', 'pus' and 'discharge' or similar terms. Other complications of tympanostomy tube insertion (such as occlusion with dry blood), as well as patients who did not have any complications, were categorised as 'no infection' on the data sheet. The time duration from insertion to infection was documented. The number of infections in the

From the Department of Otolaryngology Head and Neck Surgery, Hull Royal Infirmary, UK, the *Department of Histopathology, UC Davis Medical Centre, Sacramento, California, USA, and the †ENT Department, Royal Darwin Hospital, Northern Territory, Australia.

Accepted for publication: 28 April 2008. First published online 25 June 2008. 
TABLE I

INFECTIONS IN ABORIGINAL PATIENTS VS NON-ABORIGINAL PATIENTS, EXCLUDING THOSE NOT ATTENDING FOLLOW UP

\begin{tabular}{llrlr}
\hline Focus group & \multicolumn{2}{c}{ Infections? $(n(\%))$} & Total $(n(\%))$ & $p^{*}$ \\
\cline { 2 - 4 } & \multicolumn{1}{c}{ Yes } & No & & \\
\hline Aboriginal & $41\left(19^{\dagger}, 37^{\ddagger}\right)$ & $70\left(33^{\dagger}, 63^{\ddagger}\right)$ & $111\left(52^{\dagger}\right)$ & $0.2795-0.4664$ \\
Non-Aboriginal & $36\left(17^{\dagger}, 35^{\ddagger}\right)$ & $66\left(31^{\dagger}, 65^{\dagger}\right)$ & $102\left(48^{\dagger}\right)$ & $0.2612-0.4535$ \\
Total & $77\left(36^{\dagger}\right)$ & $136\left(64^{\dagger}\right)$ & 213 & 0.8866 \\
\hline
\end{tabular}

Relative risk $=1.047 ; 95 \%$ confidence intervals $(\mathrm{CI})$ of difference $=-0.1128$ to $0.1456 .{ }^{*}$ Two-sided. ${ }^{\dagger}$ Percentage of whole study population; ${ }^{*}$ percentage of specific focus group (i.e. Aboriginal patients or non-Aboriginal patients).

TABLE II

INFECTIONS IN ALL MALE PATIENTS VS ALL FEMALE PATIENTS, EXCLUDING THOSE NOT ATTENDING FOLLOW UP

\begin{tabular}{llcccc}
\hline Focus group & \multicolumn{2}{c}{ Infections? $(n(\%))$} & Total $(n(\%))$ & $p^{*}$ & 95\% CI \\
\cline { 2 - 4 } & \multicolumn{1}{c}{ Yes } & No & & \\
\hline Males & $51\left(24^{\dagger}, 37^{\ddagger}\right)$ & $88\left(41^{\dagger}, 63^{\ddagger}\right)$ & $139\left(65^{\dagger}\right)$ & $0.2867-0.4532$ \\
Females & $26\left(12^{\dagger}, 35^{\ddagger}\right)$ & $48\left(23^{\dagger}, 65^{\ddagger}\right)$ & $74\left(35^{\dagger}\right)$ & $0.2439-0.4709$ \\
Total & $77\left(36^{\dagger}\right)$ & $136\left(64^{\dagger}\right)$ & 213 & 0.8815 & $0.7971-1.525$ \\
\hline
\end{tabular}

Relative risk $=1.044 ; 95 \%$ confidence intervals $(\mathrm{CI})$ of difference $=-0.1200$ to $0.1511 .{ }^{*}$ Two-sided. ${ }^{\dagger}$ Percentage of whole study population; ${ }^{\ddagger}$ percentage of specific focus group (i.e. all male patients or all female patients).

two-year post-operative period was not counted, as it would have been difficult to distinguish separate episodes from a continuous infection on the basis of the medical records alone.

Patients who did not attend follow-up visits were not assumed to have no infections. A separate category was created for these patients within the data sheet. If a patient missed some of their follow-up appointments, but subsequently attended their next appointments, they were not excluded from the general focus of the study. According to a 2001 meta-analysis of 134 articles, including over 30000 ears, transient otorrhoea occurred in 26 per cent of patients after tympanostomy tube insertion. ${ }^{1}$ Therefore, assuming an increase of 20 per cent as clinically significant, a sample size of at least 98 patients in each group was calculated to be required, assuming a power of 80 per cent with a 0.5 statistical difference.

Data were analysed, using InStat3 statistical software, to determine significance. Data were analysed using contingency tables which compared infection rates between study groups pairs (i.e. Aboriginal vs non-Aboriginal, remote vs urban, etc). Fisher's exact test was used to calculate the two-sided $p$ value and the relative risk.
A request for the attainment and review of the patients' files was granted by the Royal Darwin Hospital information and privacy unit.

\section{Results}

A total of 331 patients who had undergone ventilation tube placement were identified. Of those, 245 patients satisfied our inclusion criteria. Of these, 213 patients attended all follow-up appointments within the study period. One hundred and thirty-nine of these 213 patients were male and 74 were female; 111 were Aboriginal and 102 non-Aboriginal. Ninety patients were under three years of age (35 Aboriginals and 55 non-Aboriginals), with a range of six months to 10 years of age in both groups. Infection rates were highest in May, July and December in the Aboriginal children, whereas August to October were the worst months for the nonAboriginal children. One hundred and eighteen children were from remote areas (76 Aboriginals vs 42 non-Aboriginals) and 95 were urban (35 Aboriginals vs 60 non-Aboriginals).

There was no statistically significant difference in overall infection rates between the Aboriginal and

TABLE III

INFECTIONS IN MALE ABORIGINAL PATIENTS VS FEMALE ABORIGINAL PATIENTS, EXCLUDING THOSE WHO DID NOT ATTEND FOLLOW UP

\begin{tabular}{llccc}
\hline Focus group & \multicolumn{2}{c}{ Infections? $(n(\%))$} & Total $(n(\%))$ & $p^{*}$ \\
\cline { 2 - 4 } & \multicolumn{1}{c}{ Yes } & No & & \\
\hline Male Aboriginals & $25\left(23^{\dagger}, 37^{\ddagger}\right)$ & $43\left(39^{\dagger}, 63^{\dagger}\right)$ & $68\left(61^{\dagger}\right)$ & $0.2541-0.4938$ \\
Female Aboriginals & $16\left(14^{\dagger}, 37^{\ddagger}\right)$ & $27\left(24^{\dagger}, 63^{\dagger}\right)$ & $43\left(39^{\dagger}\right)$ & $0.2295-0.5324$ \\
Total & $41\left(37^{\dagger}\right)$ & $70\left(63^{\dagger}\right)$ & 111 & 1.000 \\
\hline
\end{tabular}

Relative risk $=0.9881 ; 95 \%$ confidence intervals $(\mathrm{CI})$ of difference $=-0.1799$ to 0.1888 . ${ }^{*}$ Two-sided. ${ }^{\dagger}$ Percentage of whole study population; ${ }^{*}$ percentage of specific focus group (i.e. male Aboriginal patients or female Aboriginal patients). 
TABLE IV

INFECTIONS IN MALE NON-ABORIGINAL PATIENTS VS FEMALE NON-ABORIGINAL PATIENTS, EXCLUDING THOSE WHO DID NOT ATTEND FOLLOW UP

\begin{tabular}{|c|c|c|c|c|c|}
\hline \multirow[t]{2}{*}{ Focus group } & \multicolumn{2}{|c|}{ Infections $(n(\%))$} & \multirow[t]{2}{*}{ Total $(n(\%))$} & \multirow[t]{2}{*}{$p^{*}$} & \multirow[t]{2}{*}{$95 \% \mathrm{CI}$} \\
\hline & Yes & No & & & \\
\hline $\begin{array}{l}\text { Male non-Aboriginals } \\
\text { Female non-Aboriginals } \\
\text { Total }\end{array}$ & $\begin{array}{l}26\left(25^{\dagger}, 37^{*}\right) \\
10\left(10^{\dagger}, 32^{\ddagger}\right) \\
36\left(35^{\dagger}\right)\end{array}$ & $\begin{array}{l}45\left(44^{\dagger}, 63^{\ddagger}\right) \\
21\left(21^{\dagger}, 68^{\ddagger}\right) \\
66\left(65^{\dagger}\right)\end{array}$ & $\begin{array}{r}71\left(70^{\dagger}\right) \\
31\left(30^{\dagger}\right) \\
102\end{array}$ & 0.8223 & $\begin{array}{l}0.2549-0.4894 \\
0.1669-0.5141 \\
0.6261-2.058\end{array}$ \\
\hline
\end{tabular}

The relative risk $=1.135 ; 95 \%$ confidence intervals $(\mathrm{CI})$ of difference $=-0.1581$ to $0.2453 .{ }^{*}$ Two-sided. ${ }^{\dagger}$ Percentage of whole study population; ${ }^{\ddagger}$ percentage of specific focus group (i.e. male non-Aboriginal patients or female non-Aboriginal patients).

TABLE V

INFECTIONS IN ABORIGINAL PATIENTS AGED $\leq 3$ YRS VS NON-ABORIGINAL PATIENTS AGED $\leq 3$ YRS, EXCLUDING THOSE NOT ATTENDING FOLLOW UP

\begin{tabular}{|c|c|c|c|c|c|}
\hline \multirow[t]{2}{*}{ Focus group } & \multicolumn{2}{|c|}{ Infections? $(n(\%))$} & \multirow[t]{2}{*}{ Total $(n(\%))$} & \multirow[t]{2}{*}{$p^{*}$} & \multirow[t]{2}{*}{$95 \% \mathrm{CI}$} \\
\hline & Yes & No & & & \\
\hline $\begin{array}{l}\text { Aboriginal } \leq 3 \text { yrs } \\
\text { Non-Aboriginal } \leq 3 \text { yrs } \\
\text { Total }\end{array}$ & $\begin{array}{l}16\left(18^{\dagger}, 46^{\ddagger}\right) \\
19\left(21^{\dagger}, 35^{\ddagger}\right) \\
35\left(39^{\dagger}\right)\end{array}$ & $\begin{array}{l}19\left(21^{\dagger}, 54^{\ddagger}\right) \\
36\left(40^{\dagger}, 65^{\ddagger}\right) \\
55\left(61^{\dagger}\right)\end{array}$ & $\begin{array}{l}35\left(39^{\dagger}\right) \\
55\left(61^{\dagger}\right) \\
90\end{array}$ & 0.3756 & $\begin{array}{l}0.2885-0.6337 \\
0.2226-0.2856 \\
0.7925-2.210\end{array}$ \\
\hline
\end{tabular}

Relative risk $=1.323 ; 95 \%$ confidence intervals $(\mathrm{CI})$ of difference $=-0.09496$ to 0.3183 . ${ }^{*}$ Two-sided. ${ }^{\dagger}$ Percentage of whole study population; ${ }^{*}$ percentage of specific focus group (i.e. Aboriginal patients aged $\leq 3$ years (yrs) or non-Aboriginal patients aged $\leq 3$ years).

TABLE VI

INFECTIONS IN ABORIGINAL PATIENTS AGED > 3 YRS $V S$ NON-ABORIGINAL PATIENTS AGED > 3 YRS, EXCLUDING THOSE NOT ATTENDING FOLLOW UP

\begin{tabular}{llcccc}
\hline Focus group & \multicolumn{2}{c}{ Infections? $(n(\%))$} & \multirow{2}{*}{ Total $(n(\%))$} & $p^{*}$ & 95\% CI \\
\cline { 2 - 3 } & \multicolumn{1}{c}{ Yes } & No & & \\
\hline Aboriginal $>3$ yrs & $25\left(20^{\dagger}, 33^{\ddagger}\right)$ & $51\left(41^{\dagger}, 67^{\ddagger}\right)$ & $76\left(62^{\dagger}\right)$ & $0.2254-0.4465$ \\
Non-Aboriginal $>3$ yrs & $17\left(14^{\dagger}, 36^{\ddagger}\right)$ & $30\left(40^{\dagger}, 64^{\ddagger}\right)$ & $47\left(38^{\dagger}\right)$ & & $0.2267-0.5150$ \\
Total & $42\left(34^{\dagger}\right)$ & $81\left(66^{\dagger}\right)$ & 123 & 0.8450 & $0.5530-1.496$ \\
\hline
\end{tabular}

Relative risk $=0.9094 ; 95 \%$ confidence intervals (CI) of difference $=-0.1398$ to $0.2053 .{ }^{*}$ Two-sided. ${ }^{\dagger}$ Percentage of whole study population; ${ }^{*}$ percentage of specific focus group (i.e. Aboriginal patients aged $>3$ years (yrs) or non-Aboriginal patients aged $>3$ years).

TABLE VII

INFECTIONS IN REMOTE ABORIGINAL PATIENTS VS URBAN ABORIGINAL PATIENTS, EXCLUDING THOSE NOT ATTENDING FOR FOLLOW UP

\begin{tabular}{|c|c|c|c|c|c|}
\hline \multirow[t]{2}{*}{ Focus group } & \multicolumn{2}{|c|}{ Infections? $(n(\%))$} & \multirow[t]{2}{*}{ Total $(n(\%))$} & \multirow[t]{2}{*}{$p^{*}$} & \multirow[t]{2}{*}{$95 \% \mathrm{CI}$} \\
\hline & Yes & No & & & \\
\hline $\begin{array}{l}\text { Remote Aboriginal } \\
\text { Urban Aboriginal } \\
\text { Total }\end{array}$ & $\begin{aligned} & 32\left(27^{\dagger}, 42^{\ddagger}\right) \\
& 9\left(8^{\dagger}, 26^{\ddagger}\right) \\
& 41\left(37^{\dagger}\right)\end{aligned}$ & $\begin{array}{l}44\left(37^{\dagger}, 58^{\ddagger}\right) \\
26\left(23^{\dagger}, 74^{\ddagger}\right) \\
70\left(63^{\dagger}\right)\end{array}$ & $\begin{array}{l}76\left(64^{\dagger}\right) \\
35\left(32^{\dagger}\right) \\
111\end{array}$ & 0.1380 & $\begin{array}{l}0.3091-0.5402 \\
0.1251-0.4324 \\
0.8792-3.050\end{array}$ \\
\hline
\end{tabular}

Relative risk $=0.1380 ; 95 \%$ confidence intervals $(\mathrm{CI})$ of difference $=-0.02937$ to $0.3572 .{ }^{*}$ Two-sided. ${ }^{\dagger}$ Percentage of whole study population; ${ }^{\star}$ percentage of specific focus group (i.e. remote Aboriginal patients or urban Aboriginal patients).

non-Aboriginal children (Table I). Comparison of the outcome measure (i.e rate of infection) between the Aboriginal and non-Aboriginal groups with respect to age, sex and dwelling did not show any statistically significant differences (Tables II to VIII). Table IX shows the infection rates after including those patients who did not attend follow up; this change did not affect the results.
A review of the type of grommet placed showed that most were Armstrong Modified Beveled ${ }^{\circledR}$ (Armstrong, Tecfen Corporation, California, USA) (83 per cent), followed by Shephard ${ }^{\circledR}$ (Medtronic, Minneapolis, USA) (11 per cent), Medtronic ${ }^{\circledR} \quad$ (Medtronic, Watford, UK), Collar Button Grommets ${ }^{\circledR}$ (Invotec, Florida, USA) and Fluroplastic Grommets ${ }^{\circledR}$ (Invotec, Florida, USA). Since the majority of 
TABLE VIII

INFECTIONS IN REMOTE NON-ABORIGINAL PATIENTS VS URBAN NON-ABORIGINAL PATIENTS, EXCLUDING THOSE NOT ATTENDING FOLLOW UP

\begin{tabular}{|c|c|c|c|c|c|}
\hline \multirow[t]{2}{*}{ Focus group } & \multicolumn{2}{|c|}{ Infections? $(n(\%))$} & \multirow[t]{2}{*}{ Total $(n(\%))$} & \multirow[t]{2}{*}{$p^{*}$} & \multirow[t]{2}{*}{$95 \% \mathrm{CI}$} \\
\hline & Yes & No & & & \\
\hline Remote non-Aboriginals & $19\left(19^{\dagger}, 45^{\ddagger}\right)$ & $23\left(23^{\dagger}, 55^{\ddagger}\right)$ & $42(41)$ & & $0.2982-0.6133$ \\
\hline Urban non-Aboriginals & $17\left(17^{\dagger}, 28^{\ddagger}\right)$ & $43\left(42^{\dagger}, 72^{*}\right)$ & $60(59)$ & & $0.1748-0.4145$ \\
\hline Total & $36\left(36^{\dagger}\right)$ & $66\left(66^{\dagger}\right)$ & 102 & 0.0944 & $0.9471-2.692$ \\
\hline
\end{tabular}

The relative risk $=1.597,95 \%$ confidence intervals $(\mathrm{CI})$ of difference $=-0.01944$ to $0.3575 .{ }^{*}$ Two-sided. ${ }^{\dagger}$ Percentage of whole study population; ${ }^{*}$ percentage of specific focus group (i.e. remote non-Aboriginal patients or urban non-Aboriginal patients).

TABLE IX

INFECTIONS IN ABORIGINAL PATIENTS VS NON-ABORIGINAL PATIENTS, INCLUDING THOSE NOT ATTENDING FOR FOLLOW UP

\begin{tabular}{llrrr}
\hline Focus group & \multicolumn{2}{c}{ Infections? $(n(\%))$} & Total $(n(\%))$ & \multicolumn{2}{c}{$p^{*}$} \\
\cline { 2 - 4 } & \multicolumn{1}{c}{ Yes } & No & & \\
\hline Aboriginal & $41\left(17^{\dagger}, 31^{\ddagger}\right)$ & $91\left(37^{\dagger}, 69^{\ddagger}\right)$ & $132(54)$ & $0.2333-0.3969$ \\
Non-Aboriginal & $36\left(15^{\dagger}, 32^{\ddagger}\right)$ & $77\left(31^{\dagger}, 68^{\ddagger}\right)$ & $113(46)$ & $0.2339-0.4131$ \\
Total & $77\left(31^{\dagger}\right)$ & $168\left(69^{\dagger}\right)$ & 245 & 1.000 \\
\hline
\end{tabular}

Relative risk $=0.9750 ; 95 \%$ confidence intervals $(\mathrm{CI})$ of difference $=-0.1087$ to $0.1246 .{ }^{*}$ Two-sided. ${ }^{\dagger}$ Percentage of whole study population; ${ }^{*}$ percentage of specific focus group (i.e. Aboriginal patients (including those not attending for follow up) or nonAboriginal patients (including those not attending for follow up)).

grommets were of the Armstrong type, differences in infection rates between different grommet types were not considered.

\section{Discussion}

Aboriginals form approximately a third of the population of Australia's Northern Territory, and the vast majority inhabit remote communities. As a group, they suffer much poorer health than the general population, with a disease incidence comparable to that in developing countries and a life expectancy 20 years below the Australian average. Causative factors include high levels of unemployment and poverty, sub-optimal sanitation and hygiene, inadequate water and electricity, the physical and psychosocial effects of disposition, malnutrition, a traditional holistic approach to medicine, and lack of appropriate medical services. ${ }^{2,3}$

- Currently, there is little published information comparing infection rates after tympanostomy tube insertion in Aboriginal and non-Aboriginal populations of northern Australia

- However, evidence suggests that Aboriginals as a group have below-average health status, compared with the rest of the Australian population

- Consequently, it is intuitive to assume a higher infection rate in Aboriginal children

- This study investigated infection rates after tympanostomy and ventilation tube placement, comparing Aboriginal and non-Aboriginal children in the Northern Territory, Australia
Consequently, it is intuitive to assume a higher infection rate in Aboriginal children after tympanostomy tube insertion, and a raised threshold level for treating Aboriginal children with otitis media with effusion, with consequent effects on speech and language development. ${ }^{4-7}$

While there was no difference in infection rates between our two study groups, our results showed a 10 per cent higher post-tympanostomy tube infection rate in both Aboriginal and non-Aboriginal children (35 and 37 per cent, respectively) when compared with mean rates quoted in large international series (26 per cent). ${ }^{1}$ The Northern Territory's tropical climate and its inhabitants' limited access to health care, especially for those in remote areas, may be contributing factors.

There was no statistically significant difference between Aboriginal and non-Aboriginal children when comparing age ( $\leq 3 v s>3$ years), sex, season of surgery, or remote vs urban dwelling; however, both groups showed a statistically significant higher infection rate in remote compared with urban dwellers. Limited access to health care for remotely located patients could underlie this.

\section{Conclusion}

Whilst this study's methodology obviously suffers the inherent shortfalls of any retrospective study, it does at least cast doubt over the presumption that Aboriginal children suffer significantly higher infection rates following tympanostomy tube insertion, compared with non-Aboriginal children. A prospective study is warranted in order to explore this subject, which has tremendous implications for health care distribution. 


\section{References}

1 Kay DJ, Nelson M, Rosefeld RM. Meta-analysis of tympanostomy tube sequelae. Otolaryngol Head Neck Surg 2001; 124:374-80

2 http://www.healthinfonet.ecu.edu.au [May 2006]

3 Stokes CJ, Lehmann D, Johnston J, Manson A, Evans J, Elsbury $\mathrm{D}$ et al. Aboriginal perspective on middle ear disease in the arid zone of Western Australia. J Paediatr Child Health 2004;40:1440-754

4 Paradise JL, Feldman HM, Campbell TF, Dollaghan CA, Colborn KD. The effects of early or delayed insertion of tympanostomy tubes for persistent otitis media on developmental outcomes at the age of three years. $N$ Engl $J$ Med 2001;344:1179-1187

5 Paul R, Lynn TF, Lohr-Flanders M. History of middle ear involvement and speech/language development in late talkers. J Speech Hear Res 1993;36:1055-62

6 Roberts JE, Burchial MR, Koch MA. Otitis media in early childhood and its relationship to later phonological development. J Speech Hear Disord 1988;53:424-32
7 Rovers MM, Straatman H. The effects of ventilation tubes on language development in infants with otitis media with effusion: a randomized trial. Pediatrics 2000;106:E42

Address for correspondence:

Mr P Jassar,

Department of Otolaryngology Head and Neck Surgery,

Hull Royal Infirmary,

Anlaby Road,

Hull HU3 2JZ, UK.

E-mail: pjassar@yahoo.co.uk

Mr P Jassar takes responsibility for the integrity of the content of the paper.

Competing interests: None declared 